\title{
Comparação de três rotores feitos localmente com eixos em diferentes dimensōes extraindo energia cinética hidráulica dos rios amazônicos.
}

\author{
John Harry Harwood
}

\begin{abstract}
Resumo
Como parte de um projeto para planejar uma pequena usina hidrelétrica para uso de moradores ribeirinhos isolados, três rotores de baixo custo foram construídos: 1. Uma turbina de fluxo axial construida de madeira do local; 2 . Um rotor Savonius feito de um tambor de óleo modificado; 3 . Uma roda d'água subaxial flutuante. Cada rotor foi testado em uma armaçăo ligada ao lado de um barco. A potência, torque e velocidade de rotação foram medidos em várias velocidades d'água. Os rotores foram comparados em sua potência por unidade de área de perfil submerso, peso, facilidade de construção, potencial em escala ampliada, manutenção, resistência contra detritos de madeira flutuante e custo. A turbina de fluxo axial deu a mais alta potência medida, 40 watts por $\mathrm{m}^{2}$ em uma velocidade de água de $0,84 \mathrm{~m} . \mathrm{s}^{-1}$, que é a velocidade do rio Solimöes perto de Manaus. Aspectos do uso de tais rotores são discutidos.
\end{abstract}

\section{INTRODUÇÃo}

Grandes corpos de águas em movimento tais como os rios da Bacia Amazônica contêm consideráveis quantidades de energia por unidade de área de secção transversal. A energia cinética total por metro quadrado é dada pela equação :

$$
P=0,5 \times d \times v^{3} \ldots \ldots \ldots \ldots \ldots \ldots \ldots \ldots \ldots \ldots
$$

Onde $\mathrm{P}$ é a potência em watts que seria obtida se toda a água corresse com uma velocidade $v \mathrm{~m} . \mathrm{s}^{-1}$ e ao chegar a uma secção de $1 \mathrm{~m}^{2}$ pudesse ser parada e $\mathbf{d}$ é a densidade da água $\left(1.000 \mathrm{Kg} \cdot \mathrm{m}^{3}\right)$. Na prática, é impossível fazer com que toda a água pare, porque toda a correnteza cessaria seu movimento impedindo a continuidade do funcionamento do aparelho. Betz (1926), trabalhando com moinhos de vento concluiu que a taxa de conversão máxima é $16 / 27$ do total. Dessa maneira, a equação (I) torna-se :

$$
P_{n}=296 v^{3}
$$

É fácil extrair energia de tais águas em movimento, mas não é fácil ver se tal processo é econômico. Dois procedimentos são possíveis para tentar maximizar a potência obtida por unidade capital de custo. Um é aumentar a eficiência do aparelho. Outro é diminuir o capital de custo. Neste trabalho, a ênfase está no uso de rotores de baixo custo. Três diferentes tipos de rotores foram construídos de material disponível no local. A potência de cada um foi medida em várias velocidades de água e seus usos potenciais foram revistos.

\section{MATERIAIS E MÉTODOS}

\section{TURBINA DE FLUXo AXIAL (Fig. 1)}

Uma turbina de madeira foi construída na forma mostrada na fotografia. Basicamente, o rotor constituia-se de dois hexágonos ligados a um eixo em ângulo reto aos seus planos e passando pelo centro de cada um. O raio do círculo circunscrito de cada hexágono era de $0,75 \mathrm{~m}$ e a distância entre os dois hexágonos era $0,375 \mathrm{~m}$. Os ângulos dos hexágonos foram conectados por armações paralelas ao eixo e também diagonalmente como é mostrado. Armações perpendiculares ao eixo foram então colocadas destas diagonais, de maneira a formar grosseiramente a forma de uma lâmina de ventilador ou escada espiral. Nenhuma tentativa foi feita para regular as seis lâminas assim formadas.

$\mathrm{O}$ aro de uma roda de bicicleta foi pregado em um hexágono concentricamente a este. Isto foi usado como é descrito abaixo para medir a potência do rotor. Dois rolamentos de carro foram pregados nas pontas do eixo e $c$ rotor instalado em uma armação onde ele pudesse girar livremente como é mostrado.

(*) - Instituto Nacional de Pesquisas da Amazônia, Manaus. 


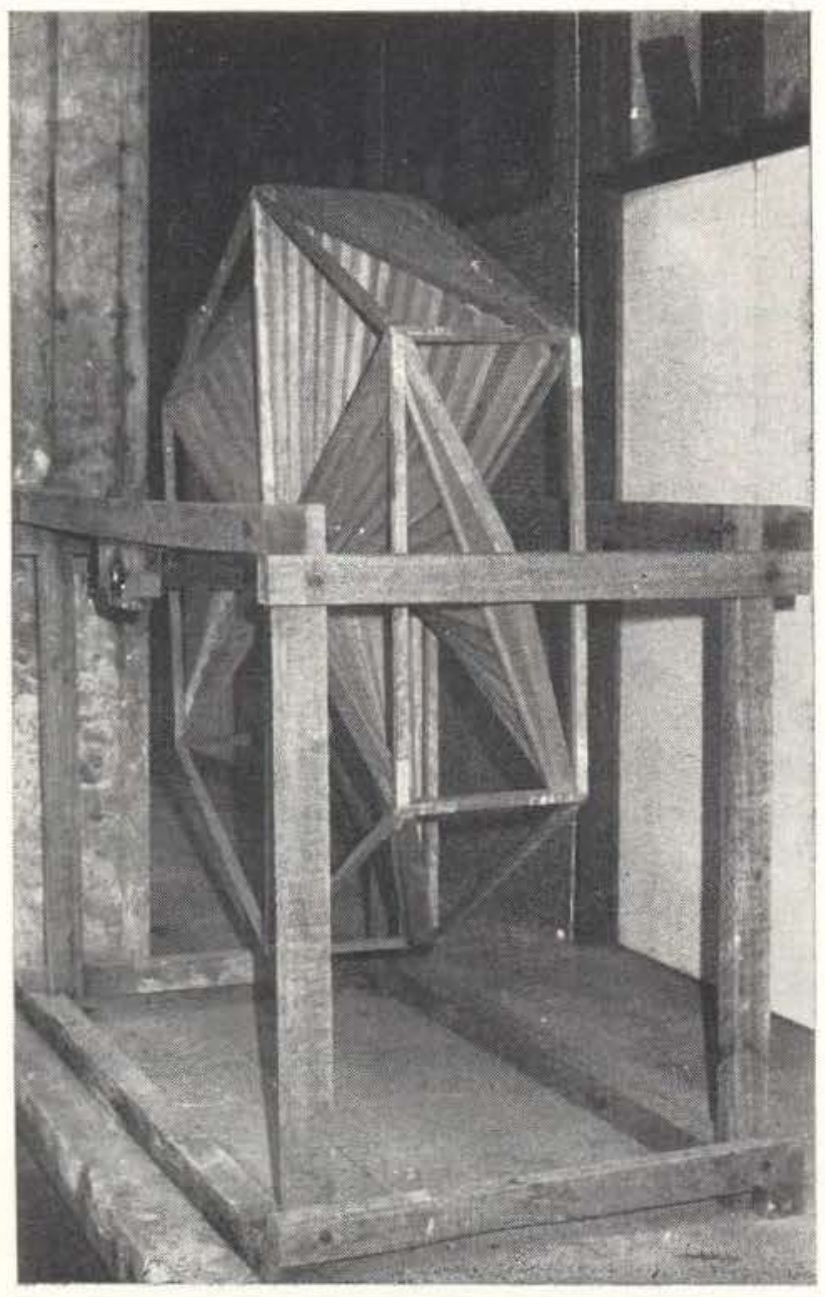

Fig. 1 - Turbina de fluxo axial.

2. ROTOR SAVONIUS (Fig. 2)

Um rotor Savonius foi construído de um tambor de óleo de 200 litros. O tambor foi cortado em dois meios-cilindros, os quais foram então colocados como é mostrado na fotografia de maneira que o diâmetro do rotor fosse $90 \mathrm{~cm}$ no ponto mais largo. Os dois meioscilindros foram mantidos nesta posição pregando-os em blocos de madeira contendo rolamentos. Um tubo de ferro galvanizado foi passado pelo rolamento para servir como eixo. O rotor foi pregado em uma armação aberta em uma posição vertical de maneira que ele pudesse girar livremente.

$\mathrm{O}$ aro de uma roda de bicicleta foi pregado na superfície superior do rotor e concêntrico com o eixo de rotação. Ele foi usado para medir a potência como é descrito adiante.

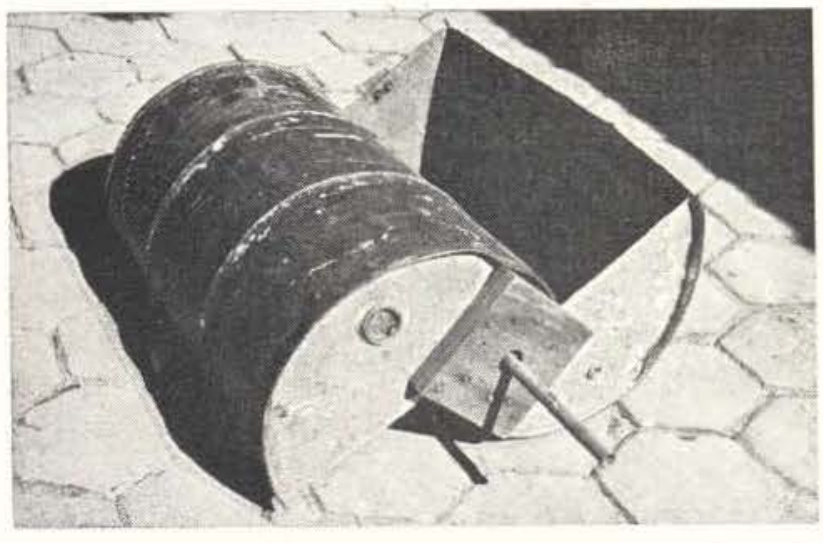

Fig. 2 - Rotor Savonius.

3. RODA D'ÁGUa Flutuante (Fig. 3)

Um tubo galvanizado, de uma polegada, foi passado simetricamente pelas extremidades furadas de um tambor de óleo de 200 litros e soldado no lugar para formar um eixo. Discos de madeira com $1 \mathrm{~m}$ de diâmetro foram colocados concentricamente neste eixo, um em cada extremidade do tambor. Doze pranchas de $90 \mathrm{~cm} \times 20 \mathrm{~cm}$ foram usadas para conectar os discos de madeira e formar pás uniformemente distribuídas ao redor da circunferência do tambor como é mostrado na fotografia.

Usou-se o aro de uma roda de bicicleta para medir a potência da roda d'água, pregando-o concentricamente a um dos discos de madeira como é descrito adiante.

\section{Montagem dos rotores :}

Cada um dos rotores foi testado da seguinte maneira : o rotor foi colocado em uma armação de madeira consideravelmente maior que ele. A armação foi pregada firmemente ao lado do barco "Pyatã" de $16 \mathrm{~m}$, usando-se cordas. A turbina de fluxo axial foi instalada com o eixo do rotor paralelo à quilha do barco. O rotor Savonius foi instalado com o eixo vertical. A roda d'água foi montada em uma armação de braço oscilante de maneira que ela flutuasse livremente. Os outros rotores foram instalados completamente submersos.

Testando os rotores :

$\mathrm{O}$ barco navegava em um local sem correnteza com uma velocidade constante em uma linha reta. A velocidade de rotação do 


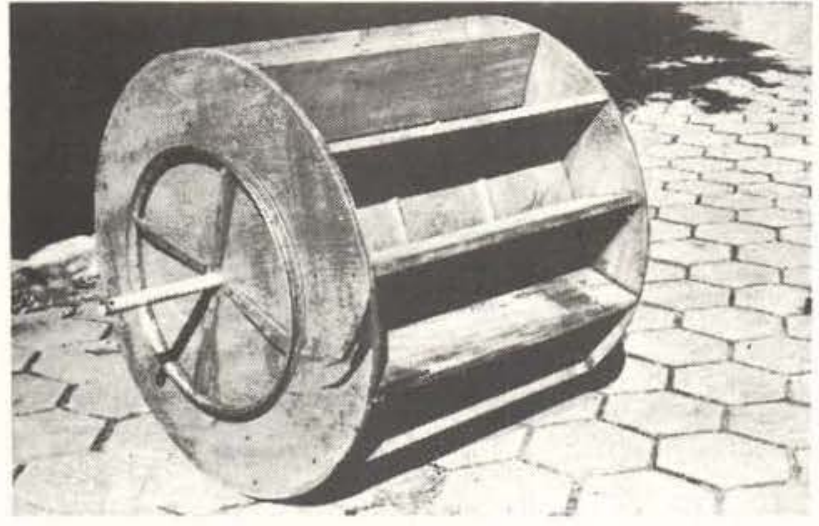

Fig. 3 - Roda d'água flutuante.

rotor sem nenhuma carga foi medida usandose um cronômetro. Dez rotações foram cronometradas três vezes. Uma corda foi então amarrada em um ponto conveniente do rotor e a tensão necessária para manter o rotor imóvel contra a força da água foi medida. Esta tensão multiplicada pelo raio no ponto de amarração dá o torque inicial do rotor.

Uma corda foi então passada ao redor do aro da bicicleta pregado ao rotor e às extremidades atadas a balanças de mola. Tensão foi aplicada às balanças de mola para diminuir a rotação, mas sem parar o rotor. Uma otimização visual foi feita para obter-se uma tensão razoável e uma velocidade do rotor razoável. A tensão foi então mantida constante nas balanças de mola e a velocidade do rotor medida novamente usando-se o cronômetro como já descrito acima.

Se $\Delta T$, medido em $\mathrm{kg}$, é a diferença das tensões nas balanças de mola, $\mathbf{g ~ m . s}$ - $^{2}$ é a aceleração devida à gravidade, $\Omega$ revoluçōes por segundo é a velocidade de rotação contra a tensão, $\mathbf{r}$ m é o raio do aro, então a potência $P$ watts é dada pela fórmula :

$$
P=\Delta T \cdot g \cdot 2 \pi r \cdot \Omega
$$

Finalmente a velocidade do barco foi calculada medindo-se o tempo levado por um pedaço de madeira lançado pela proa do barco para chegar à popa. Foram realizadas $10 \mathrm{me}$ dições e a média das medidas calculada. Um dia quando houve um vento perceptível, o barco foi ancorado e o movimento da superfície da água foi medido usando-se o mesmo método da madeira e cronômetro. A velocidade do barco foi então corrigida para o efeito do vento.

A velocidade do barco foi então mudada $e$ as medições acima repetidas. Leituras foram feitas em várias velocidades.

\section{REsultados}

Os resultados são mostrados na tabela 1 .

\section{a) Potência do rotor :}

A potência do rotor em função da velocidade da água é mostrada na figura 4. Pode ver-se que a maior potência foi obtida usandose o rotor de fluxo axial. Este foi também o maior dos rotores construídos. A velocidade do rio Solimões medida perto da margem, $200 \mathrm{~m}$ acima da entrada do canal do Paracuúba (próximo a Manaus), foi de 0,84 m.s ${ }^{-1}$. Com esta velocidade, a turbina de fluxo axial produziu 78 watts, o rotor Savonius produziu 28 watts e a roda d'água flutuante produziu 10 watts (valores interpolados da figura 1).

\section{b) Eficiência do rotor:}

Para comparar as eficiências dos rotores em uma base de unidade de área, a quantidade de energia no curso de água interceptada pelo rotor foi calculada (tabela 1, coluna g). A quantidade de energia extraída pelo rotor foi entäo expressa como uma porcentagem desta (Tabela 1, coluna h). Estes resultados são apresentados graficamente na figura 5. Podese ver que em todos os casos as eficiências diminuem com o aumento de velocidade da água. Na velocidade acima mencionada do rio Solimões $\left(0,84\right.$ m.s $\left.{ }^{-1}\right)$ a turbina de fluxo axial é a mais eficiente dos três rotores. Uma observação digna de nota é a alta eficiência do rotor Savonius em baixas velocidades da água, $\left(33 \%\right.$ a $\left.0,47 \mathrm{~m} \cdot \mathrm{s}^{-1}\right)$. 
TABELA 1 - Características de três rotores em várias velocidades de água.

\begin{tabular}{|c|c|c|c|c|c|c|c|c|c|}
\hline a & b & c & d & e & $f$ & g & h & I & j \\
\hline $\begin{array}{l}\text { Velocidade } \\
\text { da água } \\
\left.\text { (m.s } \text { - }^{-1}\right)\end{array}$ & $\begin{array}{l}\text { Torque do ro- } \\
\text { tor não gi- } \\
\text { rando }(\mathrm{N} . \mathrm{m})\end{array}$ & $\begin{array}{c}\text { Velocidade } \\
\text { de rotação } \\
\text { sem carga } \\
(r / p / s)\end{array}$ & $\begin{array}{c}\text { Velocidade } \\
\text { de rotaçāo } \\
\text { com carga } \\
(r / p / s)\end{array}$ & $\begin{array}{l}\text { Força do } \\
\text { freio } \\
\text { (Kg) } 1\end{array}$ & $\begin{array}{l}\text { Potência do } \\
\text { rotor } \\
\text { (Watts) }\end{array}$ & $\begin{array}{l}\text { Potência da } \\
\text { correnteza pas- } \\
\text { sando p/ rotor } \\
\text { (Watts) } 2\end{array}$ & $\begin{array}{l}\text { Eficiência } \\
\text { do rotor } \\
\mathrm{f} / \mathrm{g}(\%)\end{array}$ & $\begin{array}{l}\text { Tipo } \\
\text { de } \\
\text { rotor }\end{array}$ & $\begin{array}{c}\text { Area do perfil } \\
\text { da parte } \\
\text { submersa } \\
\left(\mathrm{m}^{2}\right)\end{array}$ \\
\hline 1,15 & 88 & 0,186 & 0,089 & 12,0 & 18,8 & 259 & 7 & Roda & \\
\hline 1,41 & 113 & 0,212 & 0,136 & 12,0 & 28,7 & 479 & 6 & X'ón & \\
\hline 1,64 & 142 & 0,243 & 0,149 & 14,5 & 38,0 & 752 & 5 & d’água & 0,342 \\
\hline 2,09 & 186 & - & - & - & - & - & - & flutuante & \\
\hline 0,44 & 66 & 0.152 & 0,086 & 12,5 & 18,9 & 72 & 26 & Turbina & \\
\hline 0,50 & 96 & 0,171 & 0,106 & 11,5 & 21,3 & 110 & 19 & to & \\
\hline 0.61 & 154 & 0,231 & 0,170 & 12,2 & 36,2 & 203 & 18 & de fluxo & 1.767 \\
\hline 0,89 & 206 & 0,273 & 0,224 & 21,7 & 85,2 & 620 & 14 & axial & \\
\hline 0,47 & $19-56^{3}$ & 0,210 & 0,182 & 4,0 & 12,8 & 39 & 33 & Rotor & \\
\hline 0,75 & $44-56^{3}$ & 0,278 & 0.196 & 7,0 & 24.1 & 160 & 15 & & 0,757 \\
\hline 0,92 & $\begin{array}{c}\text { passou da } \\
\text { madida }(>84)\end{array}$ & 0,286 & 0,250 & 7,0 & 30,7 & 297 & 10 & Savonius & \\
\hline
\end{tabular}

1. Esta força é a diferença das duas tensōes nas balanças de molo. Veja o texto.

2. Esta potência iguala a $0,5 \times 1.000 \times 03 \times \mathrm{i}$.

3. No caso do rotor Savonius, depende do posiçăo do rotor no seu ciclo. 


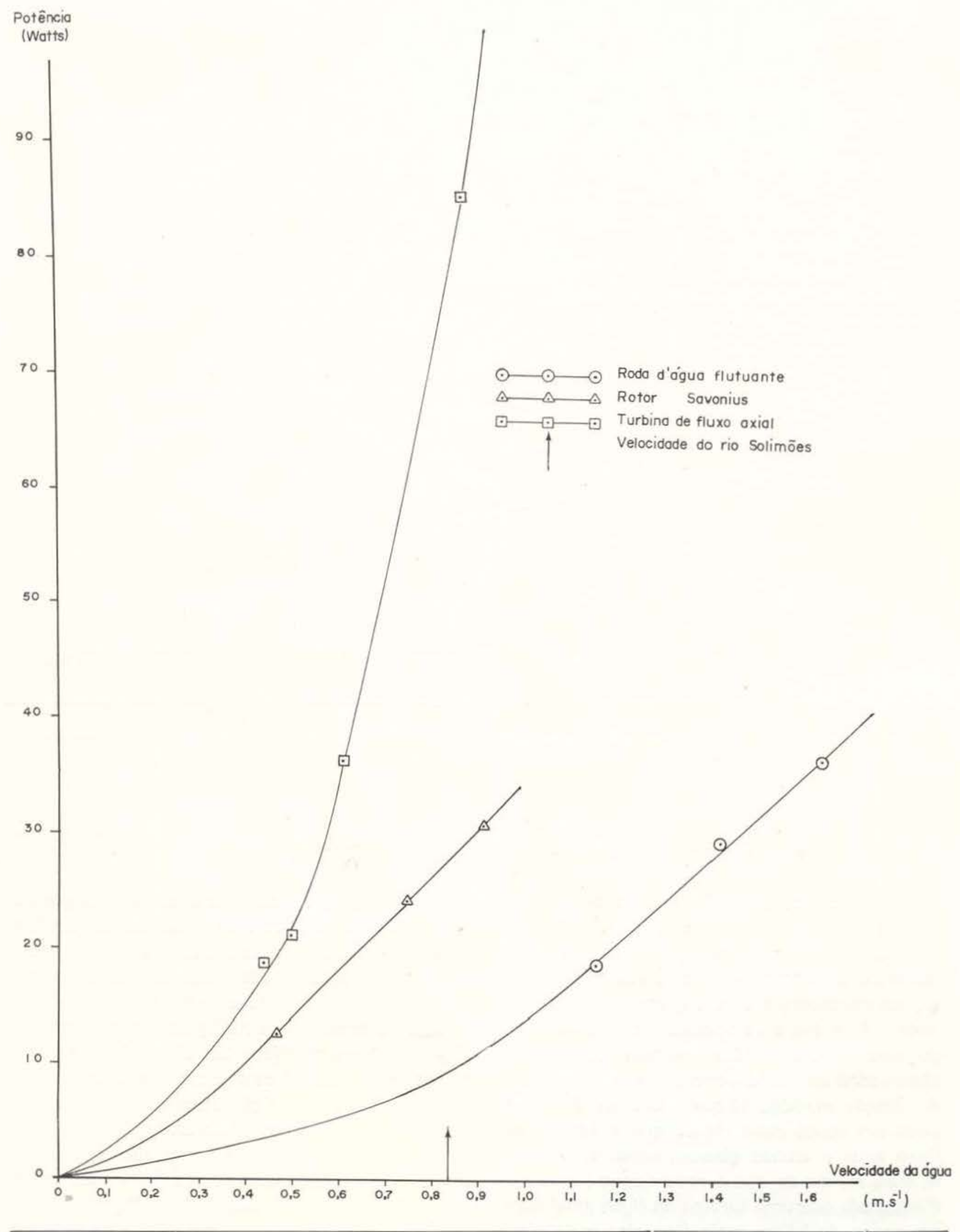

Fig. 4-Potência de três rotores a várias velocidades de água. 


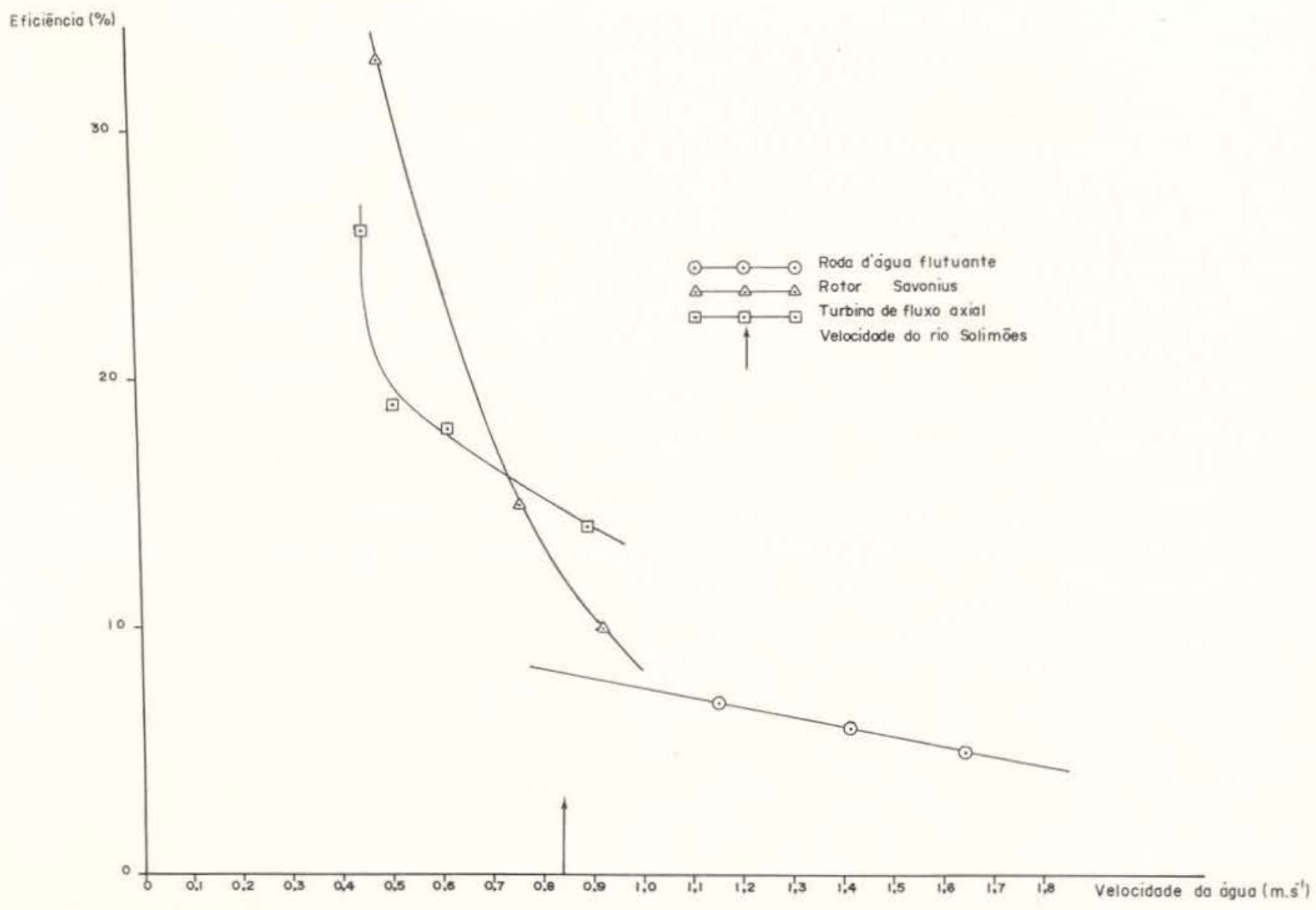

Fig. 5 - Eficiência de três rotores a várias velocidades da água.

\section{c) Velocidade rotacional livre :}

A velocidade dos três rotores sem carga é mostrada na figura 6 . Esses dados são usados para calcular a marcha necessária para aumentar a velocidade do eixo até as altas rotações necessárias para a geração de eletricidade. Eles dão a velocidade máxima possível do eixo principal. Em nenhum dos casos observados nestes experimentos, a velocidade de rotação excedeu $17 \mathrm{rpm}$. O rotor Savonius girou um pouco mais rápido que a turbina de fluxo axial e ambos giraram consideravelmen. te mais rápido do que a roda d'água flutuante. É esperado que uma turbina de fluxo axial com um passo de hélice mais fino gire mais rápido do que o rotor Savonius. d) Torque :

Na figura 7, pode observar-se o torque desenvolvido pelos rotores estacionários em função da velocidade da água. Estes dados dão uma indicação da facilidade de colocar a máquina em movimento a partir do repouso. Os valores encontrados na figura 7 não foram corrigidos para as diferentes dimensões dos rotores, e no caso do rotor Savonius, o torque ainda depende da posição do rotor com relação à correnteza da água. Este último efeito é mostrado na figura 8 . Pode ver-se que em uma velocidade de água de $0,47 \mathrm{~m} . \mathrm{s}^{-1} \mathrm{o}$ torque do rotor Savonius varia entre 19 e 56 N.m dependendo da posição do rotor. Valores minimos são mostrados na figura 7 . 


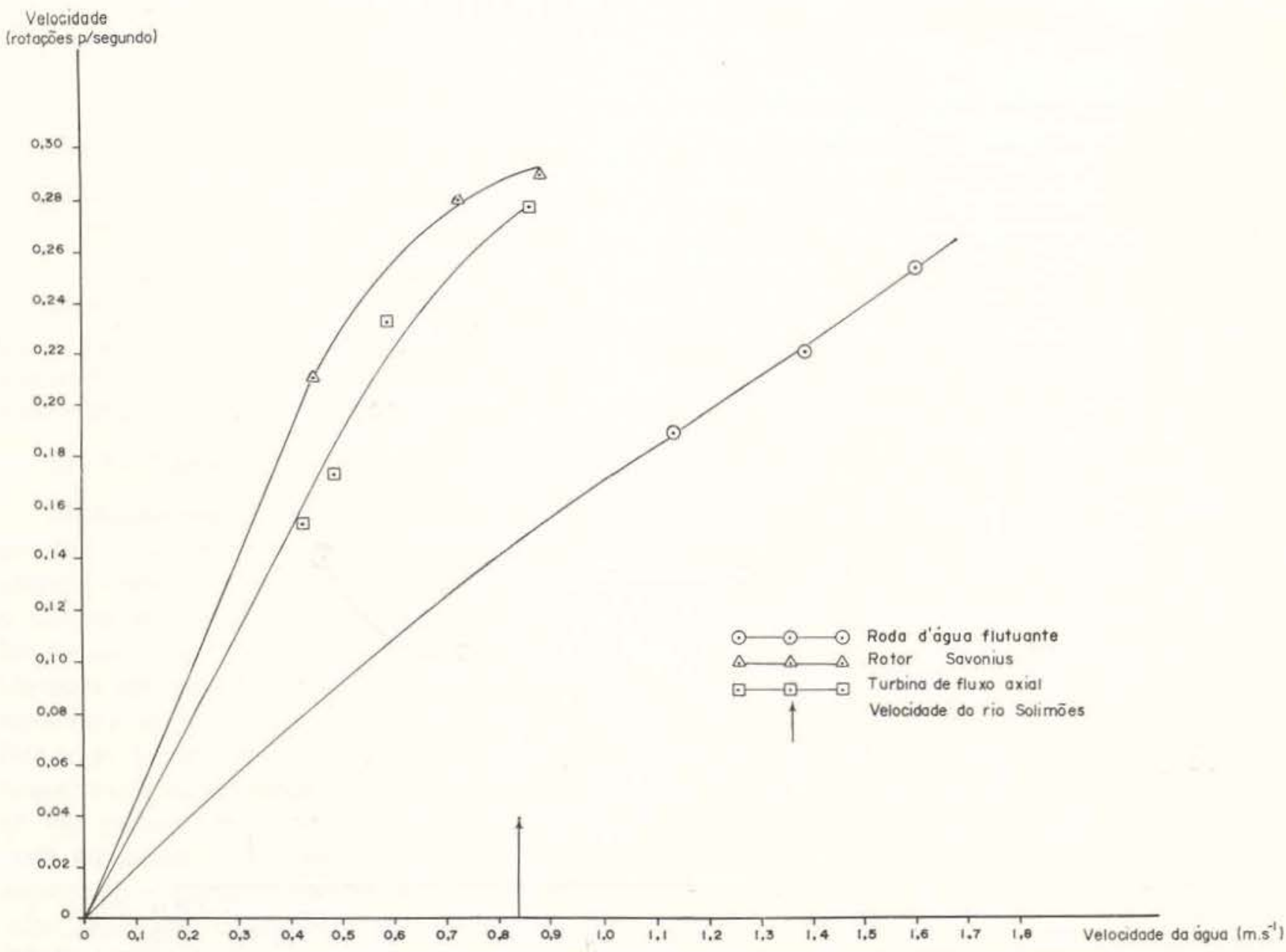

Fig. 6-Velocidade de rotação de três rotores sem carga, a várias velocidades da água.

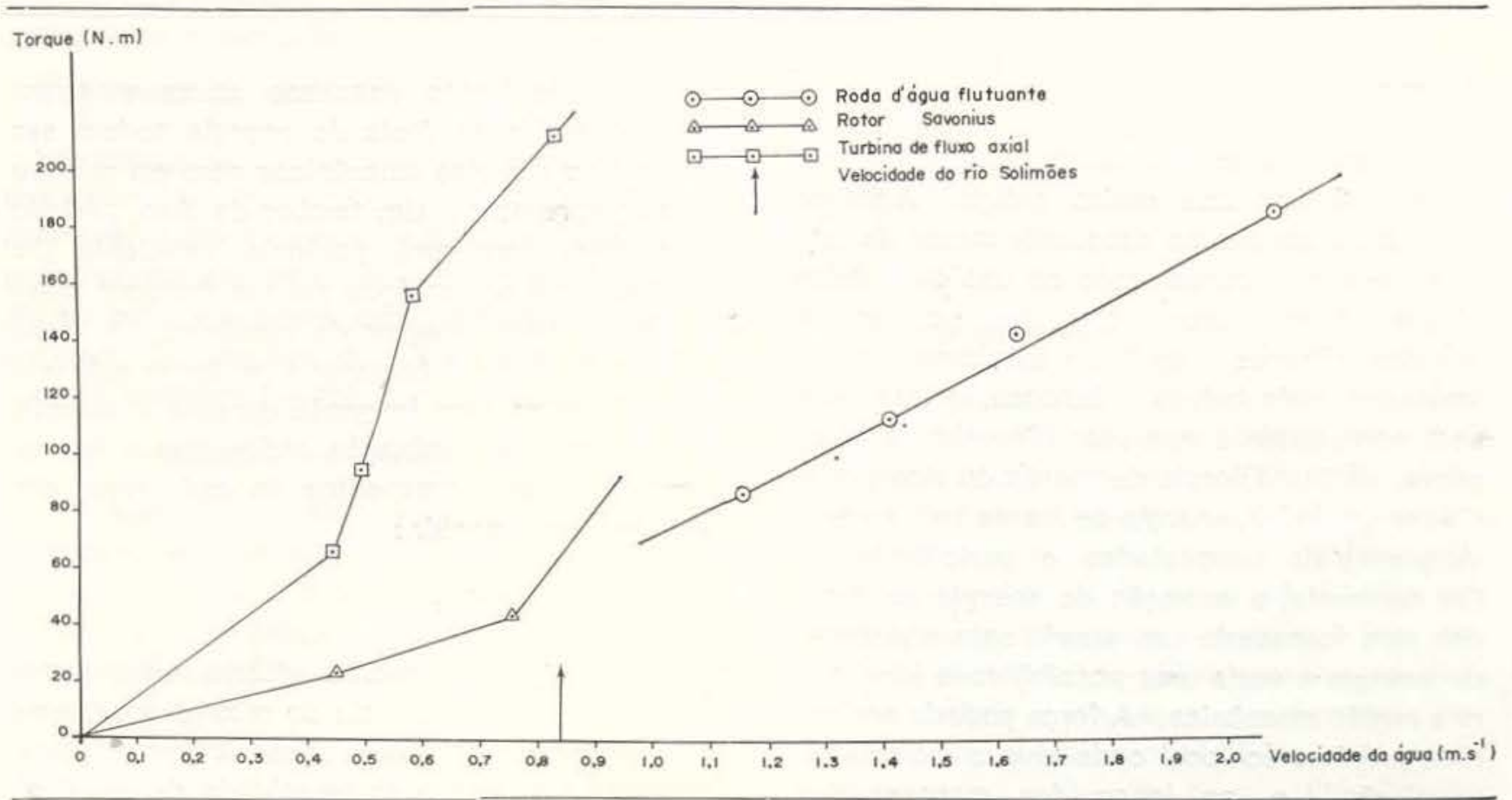

Fig. 7 - Torque de três rotores a várias velocidades de água (medido com rotor estacionário). 


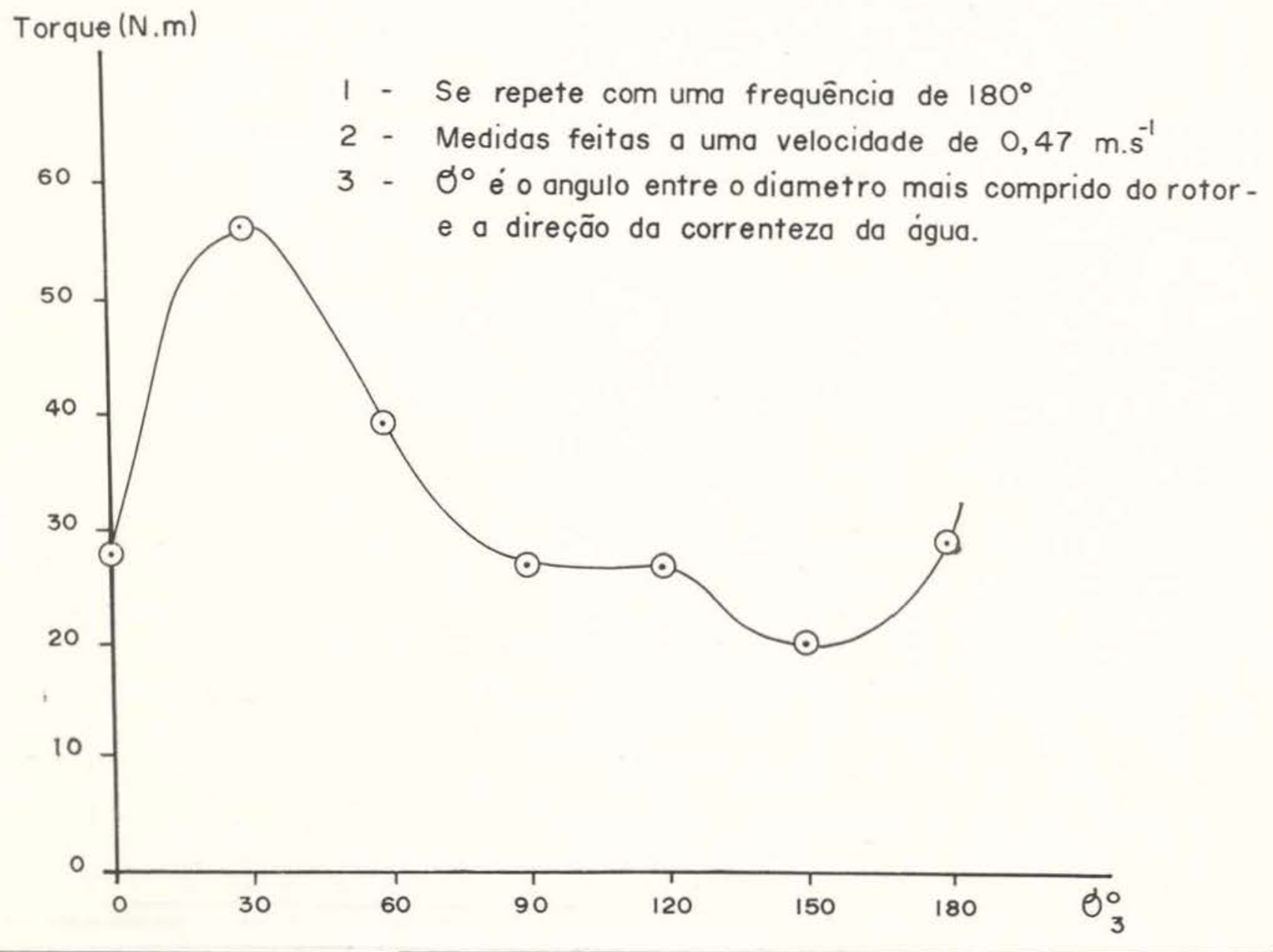

Fig. 8 - Variação do Torque de um rotor Savonius em funçâo da posição do rotor.

\section{DISCUSSÃo}

O uso da energia cinética de água em movimento é uma arte muito antiga. A maior parte do interesse no desenvolvimento de tecnologia tem-se concentrado no uso de quedas d'água. Houve pouco progresso no uso de grandes volumes d'água em movimento a velocidades mais baixas. Contudo, o interesse está começando a aparecer (Fraenkel \& Musgrove, 1979). Energia de marés ou rios poderia ser usada. A energia de marés tem as desvantagens de tempestades e periodicidades. Em contraste, a extração de energia de grandes rios forneceria um suprimento constante de energia e seria uma possibilidade ideal para a região amazônica. A força poderia ser gerada próximo ao local onde vive a maioria da população, i.e. ao longo das margens dos rios.
Os resultados descritos acima mostram que quantidades úteis de energia podem ser extraídas dos rios amazônicos com um mínimo de equipamento. Um tambor de óleo, cortado em dois, fornecerá potência suficiente $(28$ watts) para elevar água até um morador ribeirinho ou para moagem de mandioca. A turbina de fluxo axial forneceria potência suficiente (78 watts) para irrigação durante a estaçăo seca ou para iluminação rudimentar. As características e prospectos de cada rotor são discutidos a seguir :

a) Potência :

A Equação II descrita anteriormente prevê um aumento da potência do rotor proporcional ao cubo da velocidade d'água. A figura 1 mostra que o aumento da velocidade da água aumenta consideravelmente a potência de cada 
rotor. No entanto, nenhum dos rotores testados atingiu o aumento de potência na proporção exata do cubo da velocidade. A diferença entre os valores obtidos e os valores teóricos pode ser explicada pela diminuição da eficiência do rotor em função do aumento da velocidade d'água, como é mostrado na figura 5 .

Como há aumento da potência em função da velocidade d'água, está claro que em qualquer local onde se vai instalar um rotor deve investigar-se a velocidade das correntezas d'água próximas para melhor aproveitamento.

\section{b) Facilidade de construção :}

Indubitavelmente, o rotor mais fácil de ser construído é o rotor Savonius. Quase nenhum material é necessário para construi-lo, a não ser dois rolamentos de esfera, um tambor de óleo e um pedaço de cano galvanizado. Ele pode ser construído numa tarde. O outro mais fácil de ser construído é a roda d'água flutuante. Como descrito aqui, sua construção requer o uso de um maçarico, embora isto possa ser evitado com trabalho de marcenaria mais complexo. O tempo necessério para construí-lo é quase o mesmo do rotor Savonius. A turbina de fluxo axial é o rotor mais difícil de ser feito, embora os materiais sejam os mais simples. Um carpinteiro demora 2 dias para construí-lo.

\section{c) Peso do rotor:}

A roda d'água flutuante é o mais pesado dos rotores testados $(69 \mathrm{~kg})$, embora seja mais manobrável que a turbina de fluxo axial $(46 \mathrm{~kg})$, uma vez que ela roda convenientemente quando em terra e é sustentada pela água quando em uso. O rotor Savonius é o mais leve dos rotores testados $(24 \mathrm{~kg})$.

\section{d) Prospectos em escala ampliada :}

Para ser de interesse econômico, uma turbina deve ser capaz de produzir, pelo menos 300 watts. Este é o tamanho mínimo de um gerador de eletricidade à gasolina. Tal gerador, funcionando continuamente forneceria diariamente $7,2 \mathrm{KWh}$, o que facilmente excede o consumo médio per capita brasileiro em 1978 de 2,56 KWh (Ministério de Minas e Energia, 1979). Para atingir esta desejada potência, o tamanho de cada rotor aqui descrito precisaria ser aumentado.

A escala ampliada da turbina de fluxo axial é calculada a partir do aumento do diâmetro do rotor. Embora isto torne a construção do rotor mais difícil, existe a vantagem de que a velocidade tangencial, do aro do rotor aumentará com o tamanho do rotor. Isto dá a possibilidade de usar-se a circunferência do rotor como uma polia gigante para atingir a alta velocidade necessária de rotação do gerador. Uma turbina de $4 \mathrm{~m}$ de diâmetro do tipo descrito acima imersa em um rio com uma correnteza de 0,84 m.s ${ }^{-1}$ forneceria 555 watts, giraria a $13,4 \mathrm{rpm}$ e faria um gerador unido a uma roldana de $5 \mathrm{~cm}$ girar a uma velocidade de $1.072 \mathrm{rpm}$. Um gerador de 6 polos seria necessário para produzir corrente alternada na faixa de $50-60 \mathrm{~Hz}$.

Para ampliação da potência do rotor Savonius aumenta-se o número de rotores no mesmo eixo. Isto produz uma máquina poderosa e barata, no entanto existem consideráveis problemas de ordem mecânica para aumentar a velocidade do eixo para geração de eletricidade.

A roda d'água flutuante oferece a interessante possibilidade de enfileirar uma série de tais rodas lado a lado, conectadas por junçōes universais. Elas poderiam ser colocadas atravessadas de um lado a outro do rio com rolamentos nas extremidades do cabo como únicas estruturas de sustentação. Novamente o problema de baixa velocidade do cabo persiste.

\section{e) Manutenção :}

Uma vez que os rotores giram em baixa velocidade, o desgaste nas partes móveis é mínimo. A superfície do rotor deve ser pintada para evitar a ferrugem ou apodrecimento. Os rolamentos submersos devem preferencialmente ser buchas de borracha lubrificadas pela água, porém rolamentos metálicos bem engraxados funcionarão. O engraxamento destes sob a água é um pouco problemático, porém com uma pistola de lubrificação pode ser aplicada graxa suficiente para a lubrificação das esferas. 


\section{f) Madeira flutuante :}

Existe um problema em rios como o Solimões em que troncos de árvores descem flutuando. Estes podem causar danos ou bloqueio no rotor. A roda d'água flutuante é particularmente boa para lidar com este problema, uma vez que ela literalmente escalará os objetos flutuantes desde que eles não sejam muito altos. Uma corda através da água em frente da roda seria proteção suficiente.

O rotor Savonius é, até certo ponto, autoprotegido contra detritos, visto que durante o curso de rotação o fluxo de água sobre qualquer parte do rotor muda de sentido. Isto quer dizer que a madeira flutuante que entra no rotor é subseqüentemente lançada fora novamente, contudo, grandes objetos poderiam causar um problema e uma tela de malha grande em frente ao rotor seria recomendada.

A turbina de fluxo axial é a mais vulnerável uma vez que ela tem um ângulo de ataque constante. Uma tela de malha grande em frente ao rotor é recomendável, por exemplo, um gradeado de vigas em intervalos de $60 \mathrm{~cm}$. É de esperar-se que a maioria dos detritos, descendo o rio, estarão na superfície, de maneira que esta área deve ser particularmente protegida.

\section{g) Custo :}

O rotor de construção mais barato é o Savonius. Os custos em abril de 1979 são os seguintes : tambor de óleo $=\mathrm{Cr} \$ 300,00$, rolamentos de esferas $=\operatorname{Cr} \$ 100,00$, cano de ferro galvanizado $=\operatorname{Cr} \$ 150,00$, madeira e parafusos $=\operatorname{Cr} \$ 50,00$, pintura $=\operatorname{Cr} \$ 50,00$ por ano. Supondo uma vida de 5 anos, o custo do rotor será Cr\$ 0,69 por KWh localizado em uma região com uma correnteza de $0,84 \mathrm{~m} . \mathrm{s}^{-1}$.

$\mathrm{O}$ custo da roda d'água flutuante é semelhante, porém mais madeira é necessário, digamos CrS 100,00 a mais. Em vista de a potência deste rotor ser menor, o custo por KWh de força mecânica seria $\mathrm{Cr}$ \$ 1,96 sob as mesmas condições de fluxo d'água.

$\mathrm{O}$ rotor mais caro de construir-se é a turbina de fluxo axial. O custo para construir tal estrutura comercialmente seria CrS $3.000,00$.
Isto torna o custo por KWh de força mecânica Cr\$ 0,95 sob as mesmas condições de fluxo de água.

Deve ser salientado, contudo, que a ênfase na investigação destes rotores foi dada na tentativa de encontrar uma unidade que possa ser construída em casa. As economias podem por isso ser muito variáveis. Por exemplo, se um tambor de óleo perfurado é usado para fazer-se o rotor Savonius, o custo deste ítem pode ser próximo de zero. Igualmente, um trabalhador preparado para construir, ele mesmo, o rotor e descontando seu próprio tempo, pode construir uma turbina de fluxo axial por muito menos que o custo acima estabelecido.

Em sua forma atual, a turbina de fluxo axial seria de algum uso na iluminação de moradias ribeirinhas. Supondo uma conversão de $80 \%$ de energia mecânica em eletricidade, o rotor poderia fornecer força para duas lâmpadas fluorescentes de 30 watts cada uma. Alternativamente, se a eletricidade fosse gerada em baixa voltagem de corrente contínua e armazenada em baterias, suficiente eletricidade seria armazenada para fazer funcionar 3 lâmpadas de 100 wats e um televisor portátil 4 horas por dia. Nesse último caso, existe um custo extra de renovar a cada dois anos 4 baterias de $50 \mathrm{Ah}$ e 12 volts (se baterias de carro forem usadas). Também a instalação dos cabos elétricos fica mais custosa pois se necessita de cabos mais espessos para a transmissão de baixas voltagens. Em vez de ser usado para comprar um sistema de armazenamento, tal investimento extra de capital seria provavelmente melhor empregado no aumento do tamanho do rotor, para que a potência gerada seja maior, eliminando a necessidade de armazenamento de eletriicidade.

O rotor Savonius é provavelmente mais apropriado para o acionamento de uma bomba d'água. Neste caso a variação cíclica do torque produzido pelo rotor (Figura 8) pode ser importante. Se o rotor está conectado diretamente à bomba, sem marchas, deve ser colocado de maneira que produza seu torque máximo no momento em que a bomba estiver no seu tempo de força.

Trabalhos sobre aplicações desses rotores estão em andamento. 


\section{SUMMARY}

As part of a project to design a small hydro-eletric plant for use by isolated riverside dwellers three low cost rotors were constructed: (1) an axial-flow turbine constructed of local timber, (2) a Savonius rotor made out of a modified oil-drum, (3) a floating undershot water-wheel. Each rotor was tested in a frame attached to the side of a boat. The power output, starting torque and maximum speed of rotation were measured. The rotors were compared in their power output per unit area of submerged profile, weight, ease of construction, scale-up potential, maintenance requirements, ability to cope with driftwood and cost. The axial-flow turbine gave the highest measured power output, 40 watts per $\mathrm{m}^{2}$ at a water speed of $0.84 \mathrm{~m} \cdot \mathrm{s} \mathrm{s}^{-1}$, the speed of the rio Solimōes near to Manaus. Prospects for the use of such rotors are discussed.

\section{BIBLIOGRAFIA}

BETz, A.

1926 - Windenergie und ihre Ausnützung durch Windmühlen, Gottingen, Vandenhook und Rupprecht.

Fraenkel, P.L. \& Musgrove, P.J.

1979 - Tidal and River Current Energy Systems, In: Simpósio do Instituto de Engenheiros Elétricos sobre "Future Energy Concepts". Londres.

MinistÉrio de Minas E ENERGIA

1978 - Balanço Energético Nacional. Brasília.

(Aceito para publicação em 11/11/79) 